\title{
Domestication effects on behavioural and hormonal responses to acute stress in chickens
}

Maria Ericsson, Amir Fallahsharoudi, Jonas Bergquist, Mark M. Kushnir and Per Jensen

\author{
Linköping University Post Print
}

\section{Tweet}

N.B.: When citing this work, cite the original article.

Original Publication:

Maria Ericsson, Amir Fallahsharoudi, Jonas Bergquist, Mark M. Kushnir and Per Jensen, Domestication effects on behavioural and hormonal responses to acute stress in chickens, 2014, Physiology and Behavior, (133), 161-169.

http://dx.doi.org/10.1016/j.physbeh.2014.05.024

Copyright: Elsevier

http://www.elsevier.com/

Postprint available at: Linköping University Electronic Press

http://urn.kb.se/resolve?urn=urn:nbn:se:liu:diva-107167 


\section{Domestication effects on behavioural and hormonal responses to acute stress in chickens}

Maria Ericsson ${ }^{*}$, Amir Fallahsharoudi ${ }^{*}$, Jonas Bergquist ${ }^{1,2,3}$, Mark M Kushnir ${ }^{1,2,3}$, Per Jensen ${ }^{* *}$

AVIAN Behavioural Genomics and Physiology Group, IFM Biology, Linköping University, 58183 Linköping, Sweden

${ }^{1}$ Department of Chemistry, BMC, Analytical Chemistry, Uppsala University, PO Box 599, 75124 Uppsala, Sweden

${ }^{2}$ ARUP Institute for Clinical \& Experimental Pathology, 500 Chipeta Way, Salt Lake City, Utah, USA

${ }^{3}$ Department of Pathology, University of Utah School of Medicine, Salt Lake City, Utah, USA

* Equal contribution

** Corresponding author: Email: per.jensen@liu.se, Telephone: +46 13281298 


\begin{abstract}
Comparative studies have shown that alterations in physiology, morphology and behaviour have arisen due to the domestication. A driving factor behind many of the changes could be a shift in stress responses, with modified endocrine and behavioural profiles. In the present study we compared two breeds of chicken (Gallus gallus), the domestic White Leghorn (WL) egg laying breed and its ancestor, the Red Junglefowl (RJF). Birds were exposed to an acute stress event, invoked by three or ten minutes of physical restraint. They were then continuously monitored for the effects on a wide range of behaviours during a $60 \mathrm{~min}$ recovery phase. Blood samples were collected from the chicken at baseline, and after 10 and 60 min following a similar restraint stress, and the samples were analyzed for nine endogenous steroids of the HPA and HPG axis. Concentration of the steroids was determined using validated liquid chromatography tandem mass spectrometry methods. In RJF, an immediate behavioural response was observed after release from restraint in several behaviours, with a relatively fast return to baseline within one hour. In WL, some behaviours were affected for a longer period of time, and others not at all. Concentrations of corticosterone increased more in RJF, but returned faster to baseline compared to WL. A range of baseline levels for HPG-related steroids differed between the breeds, and they were generally more affected by the stress in WL than in RJF. In conclusion, RJF reacted stronger both behaviourally and physiologically to the restraint stress, but also recovered faster. This would appear to be adaptive under natural conditions, whereas the stress recovery of domesticated birds has been altered by domestication and breeding for increased reproductive output.
\end{abstract}

Keywords: corticosterone, recovery, restraint, White Leghorn, Red Junglefowl 


\section{Introduction}

Domesticated animals have evolved for thousands of years in a relatively protected environment compared to the original natural habitat, with reduced predator pressure, protection from disease and regular food supply. However, other potential stressors have replaced the natural ones, such as crowding [1,2], human presence and handling [3-6], artificial light [7] and lack of out-door space. The stressors affecting domestic animals in the human-controlled environment are therefore different than for the wild ancestors, and the ability and strategy to cope with various types of stressors may have been modified during domestication. [8].

It has been suggested that modifications in the stress response system may have been a driving force behind the numerous changes in morphology, physiology and behaviour seen in domesticates $[9,10]$. In the present study, we compare stress recovery patterns between the Red Junglefowl (RJF), which is the main ancestor of all domestic chicken breeds $[11,12]$ and a domesticated egg-laying strain, the White Leghorn (WL). RJF is known to show more fearful behaviour in a range of test situations [13], and several behaviour differences have also been described in foraging strategies and exploration patterns [14-16].

A central aspect of stress is the endocrinological response of the individual. Steroid hormones pass the blood brain barriers and act on the brain by modulation of gene expression [17] or through non genomic pathways such as modification of GABA receptor function [18]. Various studies have compared hypothalamic-pituitary-adrenal (HPA) axis reactivity of wild and domesticated animals and they suggest that attenuated HPA-axis reactivity in domesticates is common in many species including mice [19], rats [20], pigs [21], guinea pigs [10] silver foxes [22], mallard ducks [23] and salmonids [24]. Furthermore, activation of the HPA-axis suppresses the hypothalamic-pituitary-gonadal (HPG) axis in most animals through several mechanisms [25]. For instance, corticotropin releasing factor (CRF) inhibits secretion 
of gonadotropin releasing hormone (GnRH), while glucocorticoids suppress secretion of pituitary luteinizing hormone ( $\mathrm{LH})$, as well as progesterone and oestrogens from ovaries [26]. In general stress limits the efficiency of reproduction and causes economic loss to the farm. However, in contrast to the HPA-axis, the influences of domestication on the stress related function of the HPG-axis have not been explored thoroughly in any species. Some acute events, in addition to physical restraint, have been shown to induce a stress response in chickens, for example heat stress [27-29] and unpredictable light regimes [30]. Restraint stress however is a well-established method for triggering a stress response in chickens (see for example [29, 31, 32] ) where also the HPA-axis recovery has been investigated [31].

We used detailed behavioural comparisons of the behaviour of domestic chickens and their ancestors during recovery from an acute stress experience, combined with a uniquely broad assessment of changes in an array of steroid hormones. This allowed us, for the first time, to assess effects of domestication on behavioural and endocrine stress responses in chickens. In particular, we focused on the recovery process and the return to normal levels of both behaviour and concentrations of the steroids, using a similar approach as in earlier research on stress recovery [33-40].

Hence, the aims of this study were to integrate a comprehensive picture of behavioural and endocrine (steroid) responses during recovery from an acute stress experience in chickens, and to compare the response between domesticated chickens and their wild ancestors.

\section{Material and methods}

\subsection{Ethical statement}


The project was approved by the Linköping Council for Ethical Licensing of Animal Experiments; ethical permit no 122-10.

\subsection{Birds and housing}

In total 71 birds, of which 25 males and 46 females were tested. Half the birds were domesticated White leghorn (WL) and the other half were ancestral Red Jungle fowl (RJF). The RJF population in the current study originates from a wild caught group of animals from Thailand, maintained in our research facilities for about 10 generations. Carefully supervised pedigree breeding has taken place for sustaining genetic diversity in the population; however a certain degree of inbreeding is inevitable. The White Leghorn strain, SLU13, originates from a consciously outbred strain for research purposes, later selected for egg mass, but does not represent any commercial strain of birds. For further details regarding the animals, see [41].

For the behavioural studies, we used 13 birds of each sex and breed, except for the WL males where 12 birds were used, and for the hormonal studies, 10 different females from each breed were studied. The birds used for behavioural and hormonal studies were hatched in separate batches, and reared independently of each other, according to the routines outlined below. All birds were bred and raised under identical conditions in the same facilities.

The animals were hatched in automatic incubators at Linköping University and both batches, containing around 100 birds of each breed, were raised in one single group per batch in identical pens (measuring $1.5 \times 1.5 \mathrm{~m}$ and expanded gradually as the birds grew) until the age of six weeks. The pens contained feed and water ad libitum, wood shavings on the floor, and a heat lamp. The light cycle was set to 12 / 12h light / dark. The birds were wingtagged and vaccinated against Marek's Disease within the first two days after hatching. 
At the age of five to six weeks, the birds were moved to the research facility. The birds were housed both breeds together, but sex-separated in two neighbouring, identical multi-level housing pens, measuring 3,0 x 2,5 x 3,0 (W x L x H), equipped with perches and nest boxes. Water and conventional chicken feed were provided ad libitum. The floor was covered with wood shavings and the room had a light cycle set to 12 / 12 hours light /dark.

Testing of the birds commenced at the age of 23 weeks and a subset of birds were randomly chosen for testing. For the behavioural studies, birds of both sexes were used, but because of economical limitations for hormonal analysis, and considering the fact that in the egg industry only female WL are used, we decided to investigate only females for hormonal responses.

\subsection{Behaviour test}

The behaviour test took place during 14 consecutive days, and all birds were tested once. Four animals balanced for breed and sex were tested simultaneously in the same room but in separate arenas without visual contact. The arenas were constructed by four wooden frames covered with wire mesh and cardboard. The arena measured $1 \times 1 \times 2 \mathrm{~m}(\mathrm{~L} \mathrm{x} \mathrm{W} \mathrm{x} \mathrm{H})$. The roof was covered with a plastic mesh preventing birds from escaping. The floor was covered with wood shavings and the birds were provided water and conventional chicken feed ad libitum. The arena was also equipped with a perch and was lit by a spotlight. Given that chickens are social animals, social isolation during the test was considered as an additional stressor, while interference by other birds was undesired, and therefore a mirror was placed in the arena to simulate company. Using mirrors simulating a social companion has previously been used successfully [41-44]. To avoid human disturbance during the observation, the birds were video recorded by a camera that was placed in an upper corner of the arena. 
The birds were habituated in the test arena for 20 hours. Thereafter, the cameras were turned on and the birds were left undisturbed for 1 hour and 15 minutes. In order to eliminate behaviour disturbances caused by the observer when turning on the cameras, the first 15 minutes of video recordings were not included in the analysis. After $1 \mathrm{~h}$ and 15 minutes, the birds were exposed to stress through restraint. The observer entered the arena and caught the bird in a net, originally designed for fishing, with a diameter of $60 \mathrm{~cm}$, which was hung on the arena wall where the bird was left alone. After 3 min, the bird was released from the restraint. The behavioural stress recovery phase was then recorded for one hour. The total behaviour recording period thus comprised $60 \mathrm{~min}$ before and $60 \mathrm{~min}$ after the physical restraint.

\subsubsection{Ethogram and behaviour analysis}

The behaviour was recorded from the video footage using the software "The Observer XT" from Noldus Information Technology b.v, Wageningen, the Netherlands. The behaviours (Table 1; ethogram) were divided into states or events depending on duration. To obtain a baseline of the observed behaviours, the first hour of observations (undisturbed behaviour) was divided into 12 intervals of five minutes each. The frequency or duration of each behaviour was calculated for every 5 min interval, and a mean value for each bird was then calculated for the entire 60 min period, which we call the "baseline value" of a specific behaviour. During the hour of recovery, again the frequency or duration of each behaviour was obtained in 5 min intervals and the baseline values of the same individual was subtracted from each observed value. The recovery phase data were thus normalized to the corresponding baseline values, so for every 5 min interval the deviation from the baseline value was what we included in the analysis. 


\subsection{Hormonal measurements}

\subsubsection{Blood sampling:}

The animals ( 10 female RJF and 10 female WL) were placed in individual pens 10 days prior to the experiment for habituation. Each individual could see the adjacent birds and had ad libitum access to water and food. The tests were always conducted between 1300 and 1500 , and 4-6 individuals from non-adjacent cages were tested per day. The test order was randomized between the breeds and each bird was tested one time.

To measure baseline hormones, the birds were captured in the cage and a blood sample was drawn from the brachial (wing) vein within three min. Immediately after the baseline sampling, the birds were restrained in a net, and left hanging in this net (in the same way as during the behaviour tests) for $10 \mathrm{~min}$. Thereafter, a second blood sample was collected in the same way as for the baseline. After the second blood sampling, the birds were moved back to their cages and left undisturbed. The third blood draw was performed at 60 min after the initial disturbance. For each blood sample, $1.5 \mathrm{ml}$ blood from the brachial vein was collected in $2 \mathrm{ml}$ EDTA coated syringes, and stored on ice. The blood samples were centrifuged within 20 minutes (1500 g, $10 \mathrm{~min}$ ) and plasma was removed and stored at - $80^{\circ}$ $\mathrm{C}$; the samples were transported between the participating centres on dry ice.

\subsubsection{Hormonal analysis}

\subsubsection{Reagents and standards}

Testosterone (Te), estrone (E1), estradiol (E2), estriol (E3), pregnenolone (Pregn), hydroxylamine, formic acid, trifluoroacetic acid, dansyl chloride and sodium carbonate were purchased from Sigma Chemical Company (St Louis, MO). Androstenedione (A4), 
dehydroepiandrosterone (DHEA), progesterone (PROG) and corticosterone (CORT) were purchased from Steraloids Inc. (Newport, RI). The internal standards were deuterium labelled analogues of the steroids $d_{3}-T e, d_{3}-$ Pregn, $d_{4}-F, d_{3}-E$, (purchased from Cambridge Isotope Laboratories, Andover, MA), and $\mathrm{d}_{4}-\mathrm{E} 1, \mathrm{~d}_{3}-\mathrm{E} 2, \mathrm{~d}_{3}-\mathrm{E} 3$ (purchased from CDN Isotopes, Toronto, ON). All other chemicals were of the highest purity commercially available.

\subsubsection{Liquid chromatography tandem mass spectrometry}

Plasma samples were analysed for Pregn, CORT, DHEA, A4, Te, PROG, E1, E2 and E3 using liquid chromatography tandem mass spectrometry methods (LC-MS/MS) as previously described [45-47]. Briefly, steroids were extracted from samples and CORT, DHEA, A4, Pregn, and PROG were derivatized with hydroxylamine to form oxime derivatives; E1, E2 and E3 were derivatized with dansyl chloride to form dansyl derivatives. Limit of quantification (LOQ) was $0.05 \mathrm{ng} / \mathrm{ml}$ for Pregn, $1 \mathrm{ng} / \mathrm{ml}$ for PROG, $0.5 \mathrm{ng} / \mathrm{mL}$ for CORT, 0.01 for Te and A4 and $0.05 \mathrm{ng} / \mathrm{ml}$ for DHEA, $1 \mathrm{pg} / \mathrm{ml}$ for E1, E2 and E3 [45]. The intra-assay and inter-assay CV were $<8$ and $11 \%$, respectively [47]. All steroids were analysed in positive ion mode using electrospray ion source on a triple quadruple mass spectrometer (AB SCIEX Triple Quad ${ }^{\mathrm{TM}}$ 5500, Foster City, CA). The HPLC system consisted of series of 1260 and 1290 HPLC pumps (Agilent Technologies), and an HTC PAL autosampler (LEAP Technologies, NC) equipped with a fast wash station. The quadrupoles Q1 and Q3 were tuned to unit resolution and the mass spectrometer conditions were optimized for maximum signal intensity of each steroid. Two mass transitions were monitored for each steroid and its IS. Quantitative data analysis was performed using Analyst ${ }^{\mathrm{TM}}$ 1.5.2 software. Calibration curves were generated with every set of samples using six calibrators, and three quality control samples were included with every set of samples. Specificity of the analysis for each 
steroid in every sample was evaluated by comparing concentrations determined using the primary and the secondary mass transitions of each steroid and its internal standard.

\subsection{Statistics}

The behavioural variables were plotted and checked for normality prior to continued analysis. The behavioural baseline means were analysed with a factorial ANOVA, including behaviour, breed and sex in the model. Breed differences in "crowing" was determined with a t-test. To evaluate the behaviour change during the recovery phase, a repeated measures ANOVA was performed. Breed, sex and recovery time were included in the first model, and in a second analysis, effects of breed and recovery time was assessed for each sex separately. The variation is presented as standard error of the mean. The behavioural data was analysed in the software "STATISTICA 10" (StatSoft, Inc. (2011)).

A repeated measures ANOVA, including breed and time in the model, was used to evaluate breed and stress effects on hormone levels. The data are presented as means and the standard error of the men (SE). The differences were considered significant if P-values were below 0.05 . When P-values were between 0.05 and 0.1 , this was considered as a tendency.

\section{Results}

\subsection{Behaviour}

Baseline values (Tab.2) differed significantly between the breeds for "alert behaviour", "feather ruffle" and "crowing" which were more frequent in WL, while "relaxed behaviour" 
and "preen" were more frequent in RFJ. WL tended to "ground peck" more than RJF. Females showed higher baseline of "relaxed behaviour" and males displayed higher baseline levels of "feather ruffle". A significant sex x breed effect was seen in "drinking" and "wing flap", which both were performed the most by RJF males and WL females.

Considering behaviour during the recovery phase, when including both breed and sex in the model, a significant time effect was seen in several behaviours (Fig 1, Table 3). These effects were significant for "preen", "feather ruffle", "alert behaviour", and "relaxed behaviour", while there was a tendency for a time effect in "foraging session" and "wing flap". These behaviours showed an immediate response to the acute stress event, with a gradual return to baseline. Significant effects of breed during the recovery phase were seen in "foraging session" and "ground peck". An immediate increase with a fast return to baseline occurred in RJF, while in the WL, both behaviours were below baseline values during the entire observed recovery period. There was a tendency for breed effects in "relaxed behaviour", where the RJF performed less than WL during the first 25 minutes after restraint. Furthermore, a significant time $\mathrm{x}$ breed interaction was seen in "drinking", where the WL initially were affected for a longer time than the RJF. Tendencies for time $\mathrm{x}$ breed interactions were seen in "alert" and "relaxed behaviour". While "relaxed behaviour" was quite unaffected by the stress event in the WL, the behaviour was below baseline in the RJF.

A significant sex effect during recovery was found in "relaxed behaviour" and "feather ruffle", where males performed the behaviours above baseline levels to a larger extent than females. Males also tended to "wing flap" more than females after restraint. When analysing the sexes separately and comparing the breeds, no difference was seen between WL and RJF females. In males however, WL displayed reduced "ground peck" (Fig. 1k) and "foraging session" (Fig. 11) compared to RJF. A significant time x breed interaction was seen 
among females in "feeding" (Fig. 1a) where the behaviour of the WL was less affected compared to the RJF, which initially showed a small decrease compared to baseline but then rapidly increased the "feeding" behaviour. Also "drinking" (Fig. 1b) was significantly different between the breeds in females over time, and similar to "feeding", a sharp increase was initially seen in RJF. Contrary to this, "drinking" in female WL decreased after the restraint compared to the baseline. A significant between-breed difference was also seen in "relaxed behaviour" (Fig. 1f), where the WL females showed no immediate reaction and followed the baseline for the entire hour after stress, while in the RJF, there was a clear decrease of "relaxed behaviour" immediately after the stress event. No time x breed interactions were observed in the males, and there were no time $\mathrm{x}$ sex interactions.

\subsection{Hormones}

The levels of several hormones changed over time (Fig. 2 and Table 4). In WL, there was a significant change in Pregn over time (Fig. 2a) and it was lower than basal levels at min 60. Furthermore, for WL, DHEA (Fig. 2c) and A4 (Fig. 2d), but not Te (Fig. 2e) were affected, and their levels decreased from the baseline. E1 (Fig. 2f) and E2 (Fig. 2g) remained unaffected in WL.

CORT levels increased significantly 10 min after restraint in $\mathrm{WL}(\mathrm{t}=-6.3, \mathrm{P} \leq$ 0.001) and there was no significant difference between the CORT levels (Fig. 2h) at 10 and $60 \mathrm{~min}$ in the WL (levels at 10 vs $60 \mathrm{~min}: \mathrm{t}=-2.2, \mathrm{P}=0.6$ ). Similar to $\mathrm{WL}$, there was a significant rise in CORT levels after $10 \mathrm{~min}$ in $\mathrm{RJF}(\mathrm{t}=-5.5, \mathrm{P} \leq 0.001)$ but unlike WL, the CORT levels were back to baseline after $60 \mathrm{~min}$. It is worth noting that $10 \mathrm{~min}$ levels of CORT were significantly higher in $\mathrm{RJF}(\mathrm{t}=-2.3, \mathrm{P}=0.03)$. With respect to the between-breed differences, the levels of Pregn, PROG, DHEA and A4 were significantly higher in WL. The pattern of stress reactivity (time $\mathrm{x}$ breed) of Pregn, DHEA and A4 was significantly different 
between the breeds. The stress effect also tended to differ between WL and RJF for E1 and E2 (Fig. 2 and Table 4). 


\section{Discussion}

Both Red Junglefowl (RJF) and the domesticated White Leghorn (WL) layers showed an immediate response to the restraint stress, as evident from behaviour as well as endocrine changes. The reactions of the ancestral breed was more acute, with a pronounced behavioural reaction and a significant increase in corticosterone levels, whilst the recovery was slower and the overall responses sustained for a longer period in the domesticated birds. This shows that the stress response and recovery process may have been altered by domestication, probably as part of an adaptation process to living conditions under human auspice and selection for increased reproductive output. In addition, we found that corticosterone was the only one of the analysed steroid hormones which showed a clear response to the acute stress in both breeds, whereas hormones involved in the HPG axis showed breed specific levels and changes over the recovery period.

Behaviourally, RJF showed an immediate reaction in several behaviours, with a fast return to the baseline, whereas the recovery of WL was slower. In chickens, few similar studies on recovery from acute stressors have been performed, but one study on broilers observed similar sustained effects of restraint [32]. RJF has previously been shown to have stronger general fear reactions compared to WL [13], and WL has a less active response during restraint as well as a less severe response to a predator model [15]. These results are in line with the present study. A few behaviours differed between the breeds at baseline conditions, most notably in alert and relaxed behaviour. The Red Junglefowl appeared more relaxed in the experimental setting, potentially a result of the increased behavioural flexibility required from a non-domestic species.

The behavioural recovery process was not the same for all behaviours or for both sexes. In females, feeding and drinking differed significantly between the breeds over 
time, where RJF showed an immediate behaviour change followed by a fairly rapid return to baseline, while the effects were more subtle in WL. In rodents, decreased feeding can be caused by both repeated [35] and acute stress [38], and time to retain normal feeding has been found to vary dependent on type and intensity of the stressor [33, 38, 48]. Foraging behaviour in the WL did not revert to baseline during the entire hour after stress, while in RJF it did so faster, and even increased over baseline after 10-15 minutes. This indicates a rapid stress recovery. It has previously been found that feeding and exploration is less affected by chronic stress in RJF compared to WL [49], and our data show that this is also true for acute stress.

The behavioural data taken together indicate a faster recovery after an acute stress experience in RJF. This could be beneficial in the wild, where environments are more unpredictable and predators are consistent threats. A fast recovery would allow birds to resume feeding and normal behaviour as soon as the danger has disappeared. Under domestication, the ability to quickly recover from acute stress may have decreased.

For the hormone measurements, we used LC-MS/MS, which is the presently most sensitive and specific method available for measuring steroids in plasma. To our knowledge, this is the most comprehensive assessment of the steroid responses to stress in relation to domestication undertaken so far in any species, and it included effects on both final products and intermediates of the steroidogenesis pathway. However, it should be remembered that for practical reasons, we included only females in the analysis, and it is likely that there are sex differences in the endocrine stress response.

The most prominent endocrine response to the restraint episode was a rapid increase in CORT levels, which was significantly higher in RJF, followed by a decrease to the baseline levels in RJF, but not in WL. Concentrations of A4 and DHEA were significantly lower than the baseline at 60 min after restraint in WL, but no effects on concentrations of these steroids was seen in RJF. Te was not affected, and previous studies have also shown 
divergent results for this hormone [50]. DHEA is precursor of sex steroids and also known to be involved in reproduction; in addition it also has modulatory effects on female aggression [51]; chronic administration of DHEA causes inhibition of aggression in females [52].

Domesticated animals typically live in larger groups with more limited space than their wild ancestors [8]. We could speculate that the higher basal levels of DHEA in WL might be related to the greater social tolerance shown by WL females [53]. To our knowledge this is the first study which clearly shows that short term stress causes a decrease of blood DHEA levels in any avian breed, and in most species the circulating levels are very low [54].

We can only speculate about the underlying mechanisms leading to decreased levels of Preg, DHEA and A4 over time in WL but not in RJF. Adrenal pregnenolone which originates from cholesterol serves as the main precursor in adrenal steroidogenesis [55].WL had relatively high levels of CORT, 60 min after initiation of the stress test (Fig. 2h), which could have subjected them to depletion of the adrenal cholesterol resulting in lowered plasma levels of Preg, A4 and DHEA which are all mainly originated from adrenal in females. We did not find the similar pattern in RJF (Fig. 2 and Table 4). The CORT response were higher in RJF but the recovery levels was similar to the basal levels suggesting that RJF produced lower amounts of CORT over time. Besides, in RJF the basal levels of the Preg, DHEA and A4 were very low at basal levels (close to the detection levels) which would make it difficult to find any effects of stress on these hormones in RJF.

The levels of Pregn, PROG, DHEA, and A4 were higher in WL in comparison to RJF, and endocrine effects of restraint were mostly seen in WL. In birds, PROG is secreted by mature hierarchical follicles [56], stimulates LH secretion via positive feedback loop and 
leads to LH surge before the ovulation [57]. The higher PROG level which was observed in this study was therefore likely associated with the higher egg production in WL.

Other aspects of the domestication process may also be related to the observed differences in concentrations of oestrogen and androgen. For example, WL hens reach sexual maturation earlier [41], have bigger combs and higher bone density [58, 59], and produce both larger and more eggs [41]. All these different traits are genetically linked, and the observed differences in the concentrations of the steroids are likely a reflection of the changes acquired during the domestication process $[58,59]$. It has been noted in other species, that domestication and increased tameness is genetically linked to a wide array of behavioural, physiological and developmental traits and that this may be mediated via HPA and HPG axis dynamics [60].

Domestication has led to attenuated HPA reactivity in all species studied so far, while basal HPA axis activity is not necessarily affected [10, 20, 22-24]. Cockrem [61] concludes that domestic birds (chickens, Japanese quail) have lower CORT levels after stress compared to wild species of birds (Adelie penguin, Great tit), which is in line with our results. We cannot exclude the possibility that keeping the animals in mixed-breed flocks could affect their behaviour and physiology, as seen previously when keeping two genetically different layers together (Rhode Island Red and White leghorn) in mixed groups [62]. However, in previous studies, we have seen that breed differences in fear and stress reactions are not changed by housing the breeds together [13, 15].

In the present study, only one domestic variant of layers was compared to one captive population of RJF, potentially not representative for all layers and all RJF. Even though this particular group of RJF show few or no signs of the domestic phenotype [8] either with regard to behaviour, morphology or physiology, captivity might have induced changes so far undetected. Careful pedigree breeding has been carried out for minimizing the risk for 
inbreeding; however unintended selection might have occurred in the caprive population, as well as genetic drift.

Our results show that domestication has altered both behavioural and endocrine responses to acute stress in chickens. This may be relevant for understanding long term effects of different stress experiences of commercially kept birds. During breeding and rearing, chickens are exposed to a wide array of acute and chronic stress experiences, such as sex sorting, vaccination and transportation after hatching, crowding and mixing with unknown conspecifics during rearing and thwarting of various behavioural needs when kept in commercial egg laying units [63]. Understanding how birds cope with such stress is fundamental for the improvement of their welfare.

In conclusion, our results show a difference in acute stress recovery patterns, both with respect to behaviour and endocrinology, when comparing a domestic egg laying chicken breed to its wild ancestor. In general, Red Junglefowl showed a more pronounced, but short-lived response, while White Leghorns had a less severe but more long-lasting response. We therefore conclude that the domestication may have changed physiological and behavioural responses to acute stress, probably as an adaptation to a different spectrum of selection factors.

\section{Acknowledgements}

The project was supported by grants from the Swedish Research Council (VR), the Swedish Research Council for Environment, Agricultural Sciences and Spatial Planning (FORMAS), and ERC (project Genewell 322206), and within the auspice of the Swedish Centre of Excellence in Animal Welfare. For excellent technical assistance we thank Lejla Bektic. We thank ARUP Institute for Clinical and Experimental Pathology for supporting this project. 


\section{References}

[1] Siegel, H. S. The Relation Between Crowding and Weight of Adrenal Glands in Chickens. Ecology. 1959;40:495-8.

[2] Dronjak, S., Gavrilović, L., Filipović, D., Radojčić, M. B. Immobilization and cold stress affect sympatho-adrenomedullary system and pituitary-adrenocortical axis of rats exposed to long-term isolation and crowding. Physiol Behav. 2004;81:409-15.

[3] Bertin, A., Richard-Yris, M.-A., Houdelier, C., Lumineau, S., Möstl, E., Kuchar, A., et al. Habituation to humans affects yolk steroid levels and offspring phenotype in quail. Horm Behav. 2008;54:396402.

[4] Hemsworth, P. H. Human-animal interactions in livestock production. Appl Anim Behav Sci. 2003;81:185-98.

[5] Jones, R. B., Duncan, I. J. H., Hughes, B. O. The assessment of fear in domestic hens exposed to a looming human stimulus. Behav Process. 1981;6:121-33.

[6] Barnett, J. L., Hemsworth, P. H., Jones, R. B. Behavioural responses of commercially farmed laying hens to humans: evidence of stimulus generalization. Appl Anim Behav Sci. 1993;37:139-46.

[7] Morgan, K. N., Tromborg, C. T. Sources of stress in captivity. Appl Anim Behav Sci. 2007;102:262302.

[8] Price, E. O. Behavioral development in animals undergoing domestication. Appl Anim Behav Sci. 1999;65:245-71.

[9] Trut, L. N. Early Canid Domestication: The Farm-Fox Experiment: Foxes bred for tamability in a 40year experiment exhibit remarkable transformations that suggest an interplay between behavioral genetics and development. Am Sci. 1999;87:160-9.

[10] Künzl, C., Sachser, N. The behavioral endocrinology of domestication: A comparison between the domestic guinea pig (Cavia apereaf.porcellus) and its wild ancestor, the cavy (Cavia aperea). Horm Behav. 1999;35:28-37.

[11] Fumihito, A., Miyake, T., Takada, M., Shingu, R., Endo, T., Gojobori, T., et al. Monophyletic origin and unique dispersal patterns of domestic fowls. Proc Natl Acad Sci USA. 1996;93:6792-5.

[12] Tixier-Boichard, M., Bed'hom, B., Rognon, X. Chicken domestication: From archeology to genomics. C R Biol. 2011;334:197-204.

[13] Campler, M., Jöngren, M., Jensen, P. Fearfulness in red junglefowl and domesticated White Leghorn chickens. Behav Process. 2009;81:39-43.

[14] Andersson, M., Nordin, E., Jensen, P. Domestication effects on foraging strategies in fowl. Appl Anim Behav Sci. 2001;72:51-62.

[15] Schütz, K. E., Forkman, B., Jensen, P. Domestication effects on foraging strategy, social behaviour and different fear responses: a comparison between the red junglefowl (Gallus gallus) and a modern layer strain. Appl Anim Behav Sci. 2001;74:1-14.

[16] Schütz, K. E., Jensen, P. Effects of Resource Allocation on Behavioural Strategies: A Comparison of Red Junglefowl (Gallus gallus) and Two Domesticated Breeds of Poultry. Ethology. 2001;107:75365.

[17] Beato, M. Gene regulation by steroid hormones. Cell. 1989;56:335-44.

[18] Losel, R., Wehling, M. Nongenomic actions of steroid hormones. Nat Rev Mol Cell Biol. 2003;4:46-55.

[19] Treiman, D. M., Levine, S. Plasma corticosteroid response to stress in four species of wild mice. Endocrinology. 1969;84:676-80.

[20] Albert, F. W., Shchepina, O., Winter, C., Römpler, H., Teupser, D., Palme, R., et al. Phenotypic differences in behavior, physiology and neurochemistry between rats selected for tameness and for defensive aggression towards humans. Horm Behav. 2008;53:413-21.

[21] Weiler, U., Claus, R., Schnoebelen-Combes, S., Louveau, I. Influence of age and genotype on endocrine parameters and growth performance: a comparative study in Wild boars, Meishan and Large White boars. Livest Prod Sci. 1998;54:21-31. 
[22] Harri, M., Mononen, J., Ahola, L., Plyusnina, I., Rekila, T. Behavioural and physiological differences between silver foxes selected and not selected for domestic behaviour. Anim Welfare. 2003;12:305-14.

[23] Martin, J. T. Embryonic Pituitary Adrenal Axis, Behavior Development and Domestication in Birds. Am Zool. 1978;18:489-99.

[24] Woodward, C. C., Strange, R. J. Physiological stress responses in wild and hatchery-reared rainbow trout. Trans Am Fish Soc. 1987;116:574-9.

[25] Wingfield, J., Sapolsky, R. Reproduction and resistance to stress: when and how. J Neuroendocrinol. 2003;15:711-24.

[26] Chrousos, G. P., Torpy, D. J., Gold, P. W. Interactions between the hypothalamic-pituitaryadrenal axis and the female reproductive system: clinical implications. Ann Intern Med.

1998;129:229-40.

[27] Soleimani, A. F., Zulkifli, I., Omar, A. R., Raha, A. R. Physiological responses of 3 chicken breeds to acute heat stress. Poult Sci. 2011;90:1435-40.

[28] McFarlane, J. M., Curtis, S. E., Shanks, R. D., Carmer, S. G. Multiple Concurrent Stressors in Chicks.: 1. Effect on Weight Gain, Feed Intake, and Behavior. Poult Sci. 1989;68:501-9.

[29] Debut, M., Berri, C., Arnould, C., Guemené, D., Santé-Lhoutellier, V., Sellier, N., et al. Behavioural and physiological responses of three chicken breeds to pre-slaughter shackling and acute heat stress. British Poultry Science. 2005;46:527-35.

[30] Nätt, D., Lindqvist, N., Stranneheim, H., Lundeberg, J., Torjesen, P. A., Jensen, P. Inheritance of Acquired Behaviour Adaptations and Brain Gene Expression in Chickens. PLoS ONE. 2009;4:e6405.

[31] Goerlich, V. C., Nätt, D., Elfwing, M., Macdonald, B., Jensen, P. Transgenerational effects of early experience on behavioural, hormonal and gene expression responses to acute stress in the precocial chicken. Horm Behav. 2012.

[32] Marin, R. H., Freytes, P., Guzman, D., Bryan Jones, R. Effects of an acute stressor on fear and on the social reinstatement responses of domestic chicks to cagemates and strangers. Appl Anim Behav Sci. 2001;71:57-66.

[33] Rybkin, I. I., Zhou, Y., Volaufova, J., Smagin, G. N., Ryan, D. H., Harris, R. B. S. Effect of restraint stress on food intake and body weight is determined by time of day. Am J Physiol Regul Integr Comp Physiol. 1997;273:R1612-R22.

[34] Vallès, A., Martí, O., García, A., Armario, A. Single exposure to stressors causes long-lasting, stress-dependent reduction of food intake in rats. Am J Physiol Regul Integr Comp Physiol.

2000;279:R1138-R44.

[35] Martí, O., Martí, J., Armario, A. Effects of chronic stress on food intake in rats: Influence of stressor intensity and duration of daily exposure. Physiol Behav. 1994;55:747-53.

[36] Bazhan, N., Zelena, D. Food-intake regulation during stress by the hypothalamo-pituitary-adrenal axis. Brain Res Bull. 2013;95:46-53.

[37] Márquez, C., Nadal, R., Armario, A. The hypothalamic-pituitary-adrenal and glucose responses to daily repeated immobilisation stress in rats: individual differences. Neuroscience. 2004;123:60112.

[38] Márquez, C., Belda, X., Armario, A. Post-stress recovery of pituitary-adrenal hormones and glucose, but not the response during exposure to the stressor, is a marker of stress intensity in highly stressful situations. Brain Res. 2002;926:181-5.

[39] Denmark, A., Tien, D., Wong, K., Chung, A., Cachat, J., Goodspeed, J., et al. The effects of chronic social defeat stress on mouse self-grooming behavior and its patterning. Behav Brain Res.

2010;208:553-9.

[40] van Erp, A. M. M., Kruk, M. R., Meelis, W., Willekens-Bramer, D. C. Effect of environmental stressors on time course, variability and form of self-grooming in the rat: Handling, social contact, defeat, novelty, restraint and fur moistening. Behav Brain Res. 1994;65:47-55.

[41] Schütz, K., Kerje, S., Carlborg, Ö., Jacobsson, L., Andersson, L., Jensen, P. QTL Analysis of a Red Junglefowl $\times$ White Leghorn Intercross Reveals Trade-Off in Resource Allocation Between Behavior and Production Traits. Behav Genet. 2002;32:423-33. 
[42] Feltenstein, M. W., Ford, N. G., Freeman, K. B., Sufka, K. J. Dissociation of stress behaviors in the chick social-separation-stress procedure. Physiol Behav. 2002;75:675-9.

[43] Montevecchi, W. A., Noel, P. E. Temporal effects of mirror-image stimulation on pecking and peeping in isolate, pair- and group-reared domestic chicks. Behavioral Biology. 1978;23:531-5.

[44] Gallup, G. G., Montevecchi, W. A., Swanson, E. T. Motivational properties of mirror-image stimulation in the domestic chicken. The Psychological Record. 1972;22:193-9.

[45] Kushnir, M. M., Rockwood, A. L., Roberts, W. L., Pattison, E. G., Bunker, A. M., Fitzgerald, R. L., et al. Performance characteristics of a novel tandem mass spectrometry assay for serum testosterone. Clin Chem. 2006;52:120-8.

[46] Kushnir, M. M., Neilson, R., Roberts, W. L., Rockwood, A. L. Cortisol and cortisone analysis in serum and plasma by atmospheric pressure photoionization tandem mass spectrometry. Clin Biochem. 2004;37:357-62.

[47] Kushnir, M. M., Blamires, T., Rockwood, A. L., Roberts, W. L., Yue, B., Erdogan, E., et al. Liquid chromatography-tandem mass spectrometry assay for androstenedione, dehydroepiandrosterone, and testosterone with pediatric and adult reference intervals. Clin Chem. 2010;56:1138-47.

[48] Mercier, S., Frédéric, Canini, Buguet, A., Cespuglio, R., Martin, S., et al. Behavioural changes after an acute stress: stressor and test types influences. Behav Brain Res. 2003;139:167-75.

[49] Lindqvist, C., Jensen, P. Domestication and stress effects on contrafreeloading and spatial learning performance in red jungle fowl (Gallus gallus) and White Leghorn layers. Behav Process. 2009;81:80-4.

[50] Heiblum, R., Arnon, E., Gvaryahu, G., Robinzon, B., Snapir, N. Short-term stress increases testosterone secretion from testes in male domestic fowl. Gen Comp Endocrinol. 2000;120:55-66.

[51] Compagnone, N. A., Mellon, S. H. Neurosteroids: biosynthesis and function of these novel neuromodulators. Front Neuroendocrin. 2000;21:1-56.

[52] Nelson, R. J. Biology of aggression: Oxford University Press New York, NY; 2006.

[53] Väisänen, J., Jensen, P. Social versus exploration and foraging motivation in young red junglefowl (Gallus gallus) and White Leghorn layers. Appl Anim Behav Sci. 2003;84:139-58.

[54] Labrie, F., Belanger, A., Lin, S., Simard, J., Pelletier, G., Labrie, C. Is dehydroepiandrosterone a hormone? J Endocrinol. 2005;187:169-96.

[55] Siegel, H. S. Physiological Stress in Birds. Bioscience. 1980;30:529-34.

[56] Etches, R. The ovulatory cycle of the hen. Crit Rev Poult Biol. 1990;2:293-318.

[57] Johnson, P. A., Johnson, A., Van Tienhoven, A. Evidence for a positive feedback interaction between progesterone and luteinizing hormone in the induction of ovulation in the hen, Gallus domesticus. Gen Comp Endocrinol. 1985;58:478-85.

[58] Wright, D., Kerje, S., Brändström, H., Schütz, K., Kindmark, A., Andersson, L., et al. The genetic architecture of a female sexual ornament. Evolution. 2008;62:86-98.

[59] Wright, D., Rubin, C., Schutz, K., Kerje, S., Kindmark, A. A. J. o. P.-R., Integrative and Comparative Physiology, Brandstrom, $\mathrm{H}$., et al. Onset of sexual maturity in female chickens is genetically linked to loci associated with fecundity and a sexual ornament. Reprod Domest Anim. 2012;47 Suppl 1:31-6. [60] Trut, L., Oskina, I., Kharlamova, A. Animal evolution during domestication: the domesticated fox as a model. Bioessays. 2009;31:349-60.

[61] Cockrem, J. F. Stress, corticosterone responses and avian personalities. J Ornithol. 2007;148:16978.

[62] Uitdehaag, K. A., Rodenburg, T. B., van Hierden, Y. M., Bolhuis, J. E., Toscano, M. J., Nicol, C. J., et al. Effects of mixed housing of birds from two genetic lines of laying hens on open field and manual restraint responses. Behav Process. 2008;79:13-8.

[63] Appleby, M. C., Mench, J. A., Hughes, B. O. Poultry Behaviour and Welfare: CABI Pub.; 2004.

[64] Eklund, B., Jensen, P. Domestication effects on behavioural synchronization and individual distances in chickens (Gallus gallus). Behav Process. 2011;86:250-6. 
Table 1. The ethogram used for the behavioural recordings, including their definitions. It is based on the standard ethogram used in our research group [64].

\section{Behaviour Definition}

Feeding Feeding from food container

Drinking Dipping beak into water bell

Ground Distinct peck with beak on the ground

peck

Foraging Focus on the floor, pecking and scratching the ground

session

Alert Stand, sit or walk with eyes opened and raised neck, attendant to the surroundings but not behaviour to floor, feed- or water-bell

Relaxed Stand, sit or walk with reduced attention with no alert head movements and short neck. In behaviour standing and sitting, eyes may be partially closed

Freeze $\quad$ Stiff posture, stand, sit or lie motionless, vigilant, open eyes

Escape Attempt to escape from the test arena by jumping or making fly attempts towards the roof.

Run Two or more steps in considerable faster tempo than walking, body often stretched, head held in a more forward position than during walking

Preen Uses beak to trim and arrange feathers

Dust bath Squatting dust onto body, performs vertical wing shake, and rubbing the body against the ground. Usually proceeded by scratching and bill raking

Wing flap Flaps wings while standing on ground or perch

Feather Erects feathers, ruffles, and shakes body

ruffle

Crowing Cockerel crowing 
Table 2. Behavioural baseline values (frequencies for Wing flap, Feather ruffle and Crowing, duration in seconds for the rest) recorded during one hour before stress exposure, with breeds (Red Junglefowl, RJF; White Leghorn, WL) and sexes (Males, M; Females, F) presented separately as mean values \pm standard deviations. F and P-values calculated by an ANOVA are shown for significant data $(\mathrm{P}<0.05)$ and for tendencies $(0.05<\mathrm{P}<0.1)$. ns $=$ not significant $(\mathrm{P}>0.1), \mathrm{na}=$ not available or not applicable.

\begin{tabular}{|c|c|c|c|c|c|c|c|}
\hline \multicolumn{3}{|c|}{ RJF } & \multicolumn{2}{|c|}{ WL } & \multirow[b]{2}{*}{$\begin{array}{r}\text { Breed } \\
\text { effect }\end{array}$} & \multirow[b]{2}{*}{ Sex effect } & \multirow[b]{2}{*}{ Sex $*$ Breed effec } \\
\hline Behaviour & $\mathbf{M}$ & $\mathbf{F}$ & $\mathbf{M}$ & $\mathbf{F}$ & & & \\
\hline Feeding & $57.3 \pm 49.6$ & $31.1 \pm 53.3$ & $46.9 \pm 31.3$ & $36.5 \pm 38.9$ & ns & ns & ns \\
\hline Drinking & $19.3 \pm 19.5$ & $5.5 \pm 7.6$ & $9.5 \pm 8.9$ & $20.8 \pm 17.0$ & ns & ns & $\begin{array}{c}F=9.8 \\
P=0.003\end{array}$ \\
\hline $\begin{array}{l}\text { Ground } \\
\text { peck }\end{array}$ & $13.8 \pm 16.4$ & $23.0 \pm 29.8$ & $33.6 \pm 41.7$ & $40.9 \pm 48.0$ & $\begin{array}{c}F=3.5 \\
P=0.06\end{array}$ & ns & ns \\
\hline $\begin{array}{l}\text { Foraging } \\
\text { session }\end{array}$ & $15.9 \pm 25.4$ & $27.6 \pm 40.6$ & $35.7 \pm 54.1$ & $44.3 \pm 55.4$ & ns & ns & ns \\
\hline $\begin{array}{l}\text { Alert } \\
\text { behaviour }\end{array}$ & $121.8 \pm 47.9$ & $124.8 \pm 60.4$ & $170.3 \pm 28.1$ & $173.7 \pm 60.7$ & $\begin{array}{l}F=11.4 \\
P=0.001\end{array}$ & ns & ns \\
\hline $\begin{array}{l}\text { Relaxed } \\
\text { behaviour }\end{array}$ & $5.2 \pm 10.4$ & $58.4 \pm 57.9$ & $4.4 \pm 9.7$ & $1.5 \pm 3.2$ & $\begin{array}{c}F=11.7 \\
P=0.001\end{array}$ & $\begin{array}{c}F=8.9 \\
P=0.005\end{array}$ & ns \\
\hline Preen & $71.0 \pm 59.4$ & $51.8 \pm 64.0$ & $31.5 \pm 29.5$ & $17.9 \pm 18.5$ & $\begin{array}{c}F=7.7 \\
P=0.008\end{array}$ & ns & ns \\
\hline Dust bath & $6.6 \pm 23.3$ & - & - & - & ns & ns & ns \\
\hline Wing flap & $0.8 \pm 0.3$ & $0.2 \pm 0.3$ & $0.4 \pm 0.3$ & $1.0 \pm 1.2$ & ns & ns & $\begin{array}{c}F=11.7 \\
P=0.001\end{array}$ \\
\hline $\begin{array}{l}\text { Feather } \\
\text { ruffle }\end{array}$ & $0.2 \pm 0.1$ & $0.1 \pm 0.1$ & $0.4 \pm 0.2$ & $0.3 \pm 0.2$ & $\begin{array}{c}F=18.9 \\
P<0.001\end{array}$ & $\begin{array}{c}F=9.0 \\
P=0.004\end{array}$ & ns \\
\hline Crowing & $0.6 \pm 0.9$ & na & $2.2 \pm 1.9$ & na & $\begin{array}{c}\mathrm{t}=2.78 \\
\mathrm{P}=0.01\end{array}$ & na & na \\
\hline
\end{tabular}


Table. 3. Results of the repeated measures ANOVA on behavior variables shown in Fig 1. F and $\mathrm{P}$-values are shown for significant data $(\mathrm{P}<0.05)$ and for tendencies $(0.05<\mathrm{P}<0.1)$. ns $=$ not significant $(\mathrm{P}>0.1)$, na $=$ not available or not applicable.

\begin{tabular}{|c|c|c|c|c|c|c|c|c|}
\hline \multirow{2}{*}{ Behaviour } & \multicolumn{3}{|c|}{$\underline{\text { Time effect }}$} & \multicolumn{2}{|c|}{ Breed effect } & \multicolumn{2}{|c|}{$\underline{\text { Time } * \text { Breed effect }}$} & \multirow{2}{*}{$\begin{array}{l}\text { Sex effect } \\
\\
\text { Males vs } \\
\text { Females }\end{array}$} \\
\hline & All & Males & Females & $\begin{array}{c}\text { RJF vs } \\
\text { WL }\end{array}$ & Males & $\begin{array}{c}\text { RJF vs } \\
\text { WL }\end{array}$ & Females & \\
\hline Feeding & ns & ns & ns & $\mathrm{ns}$ & ns & ns & $\begin{array}{c}F=1.8 \\
P=0.05\end{array}$ & ns \\
\hline Drinking & ns & ns & ns & ns & ns & $\begin{array}{c}F=1.8 \\
P=0.05\end{array}$ & $\begin{array}{c}F=2.0 \\
P=0.03\end{array}$ & $\mathrm{~ns}$ \\
\hline $\begin{array}{l}\text { Ground } \\
\text { peck }\end{array}$ & ns & ns & ns & $\begin{array}{c}F=7.7 \\
P=0.008\end{array}$ & $\begin{array}{c}F=6.2 \\
P=0.02\end{array}$ & ns & ns & ns \\
\hline $\begin{array}{l}\text { Foraging } \\
\text { session }\end{array}$ & $\begin{array}{c}F=1.2 \\
P=0.09\end{array}$ & $\begin{array}{c}F=1.7 \\
P=0.08\end{array}$ & ns & $\begin{array}{c}F=4.5 \\
P=0.04\end{array}$ & $\begin{array}{c}F=3.1 \\
P=0.09\end{array}$ & ns & ns & ns \\
\hline $\begin{array}{l}\text { Alert } \\
\text { behaviour }\end{array}$ & $\begin{array}{c}F=5.3 \\
P<0.001\end{array}$ & $\begin{array}{c}F=4.1 \\
P<0.001\end{array}$ & $\begin{array}{l}\mathrm{F}=2.3 \\
\mathrm{P}=0.01\end{array}$ & ns & ns & $\begin{array}{c}F=1.6 \\
P=0.09\end{array}$ & ns & $\mathrm{ns}$ \\
\hline $\begin{array}{l}\text { Relaxed } \\
\text { behaviour }\end{array}$ & $\begin{array}{c}F=2.9 \\
P=0.001\end{array}$ & ns & $\begin{array}{l}\mathrm{F}=2.3 \\
\mathrm{P}=0.01\end{array}$ & $\begin{array}{c}F=3.2 \\
P=0.08\end{array}$ & ns & $\begin{array}{c}F=1.6 \\
P=0.08\end{array}$ & $\begin{array}{c}F=2.4 \\
P=0.008\end{array}$ & $\begin{array}{c}F=5.0 \\
P=0.03\end{array}$ \\
\hline Preen & $\begin{array}{c}F=2.3 \\
P=0.01\end{array}$ & $\mathrm{~ns}$ & $\begin{array}{l}\mathrm{F}=1.7 \\
\mathrm{P}=0.08\end{array}$ & ns & ns & $\mathrm{ns}$ & ns & ns \\
\hline Dust bath & ns & ns & & $\mathrm{ns}$ & ns & ns & $\mathrm{ns}$ & ns \\
\hline Wing flap & $\begin{array}{c}F=1.7 \\
P=0.069\end{array}$ & $\mathrm{~ns}$ & $\mathrm{~ns}$ & ns & ns & ns & ns & $\begin{array}{c}F=3.1 \\
P=0.08\end{array}$ \\
\hline $\begin{array}{l}\text { Feather } \\
\text { ruffle }\end{array}$ & $\begin{array}{c}F=2.9 \\
P=0.001\end{array}$ & $\begin{array}{c}F=3.6 \\
P<0.001\end{array}$ & $\mathrm{~ns}$ & ns & ns & ns & $\mathrm{ns}$ & $\begin{array}{c}\mathrm{F}=4.1 \\
\mathrm{P}=0.05\end{array}$ \\
\hline Crowing & na & $\begin{array}{c}F=2.9 \\
P=0.001\end{array}$ & na & na & ns & na & na & na \\
\hline
\end{tabular}


Table. 4. Results of the statistical analysis of hormonal variables shown in Fig 2. The analysis is based on repeated measures ANOVA with time and breed in the model .F and P values are given for breed, time and time $\mathrm{x}$ breed effects. .. Time effects are shown for White Leghorns $(\mathrm{WL})$ and Red Junglefowl (RJF) separately. Pregn = pregnelonone, $\mathrm{PROG}=$ progesterone, DHEA $=$ dehydroepiandrosterone, $\mathrm{A} 4=$ androstenione, $\mathrm{Te}=$ testosterone, $\mathrm{E} 1=$ estrone, $\mathrm{E} 2=$ estradiol, E3 = estriol, CORT $=$ corticosterone. $\mathrm{F}$ and $\mathrm{P}$-values are shown for significant data $(\mathrm{P}<0.05)$ and for tendencies $(0.05<\mathrm{P}<0.1) . \mathrm{ns}=$ not significant $(\mathrm{P}>0.1)$.

\begin{tabular}{|c|c|c|c|c|c|c|c|c|}
\hline \multirow[t]{3}{*}{ Hormone } & \multicolumn{2}{|c|}{ Breed effect } & \multicolumn{2}{|c|}{ Time * Breed effect } & \multicolumn{4}{|c|}{$\underline{\text { Time effect }}$} \\
\hline & & & & & \multicolumn{2}{|c|}{ WL } & \multicolumn{2}{|c|}{ RJF } \\
\hline & $\mathbf{F}$ & $\mathbf{P}$ & $\mathbf{F}$ & $\mathbf{P}$ & $\mathbf{F}$ & $\mathbf{P}$ & $\mathbf{F}$ & $\mathbf{P}$ \\
\hline Pregn & 5.7 & $<0.05$ & 14.2 & 0.001 & 9.5 & $<0.05$ & 4.4 & $\mathrm{~ns}$ \\
\hline PROG & 13.3 & $<0.01$ & - & $\mathrm{ns}$ & - & $\mathrm{ns}$ & 0.9 & $\mathrm{~ns}$ \\
\hline DHEA & 10.3 & $<0.01$ & 16.0 & 0.001 & 40.2 & $<0.001$ & 0.8 & $\mathrm{~ns}$ \\
\hline A4 & 8.7 & $<0.01$ & 4.1 & 0.06 & 11.9 & $<0.01$ & 2.6 & $\mathrm{~ns}$ \\
\hline $\mathbf{T e}$ & - & ns & - & $\mathrm{ns}$ & - & $\mathrm{ns}$ & 1 & $\mathrm{~ns}$ \\
\hline E1 & - & $\mathrm{ns}$ & 3.0 & 0.1 & - & $\mathrm{ns}$ & 4 & $<0.1$ \\
\hline E2 & - & ns & 3.2 & 0.1 & - & $\mathrm{ns}$ & 6 & $<0.05$ \\
\hline CORT & - & $\mathrm{ns}$ & - & $\mathrm{ns}$ & 5.3 & $<0.05$ & 22.3 & $<0.001$ \\
\hline
\end{tabular}


Legends to figures:

\section{Figure 1}

Behavioural responses to restraint: Mean frequencies or durations ( \pm S.E.M) of the recorded behaviour patterns for each 5 min interval during 60 min following 3 min restraint. All values are normalized against the baseline values (calculated as the mean frequency or duration of the behaviour during $60 \mathrm{~min}$ immediately preceding the restraint) where 0 represents the baseline. The diagrams show values for females $(a-i ; n=26)$ and males $(j-s ; n=$ 25) separately.

\section{Figure 2}

Hormonal responses to restraint: Serum concentrations of pregnenolone, progesterone, dehydroepiandrosterone (DHEA), androstenedione, testosterone, estrone, estradiol and corticosterone in female domestic White Leghorn (WL; n=10) and wild Red Junglefowl (RJF; $\mathrm{n}=10$ ). Blood sampling was performed at baseline and at 10 and $60 \mathrm{~min}$ after a $10 \mathrm{~min}$ physical restraint experience. The values are given as mean $( \pm$ S.E.M). Asterisks indicates significant differences $(*=0.05<\mathrm{P}>0.01 ; * *=\mathrm{P}<0.01)$. 
$\cdots \cdot \mathrm{RJF}$
$-\mathrm{WL}$
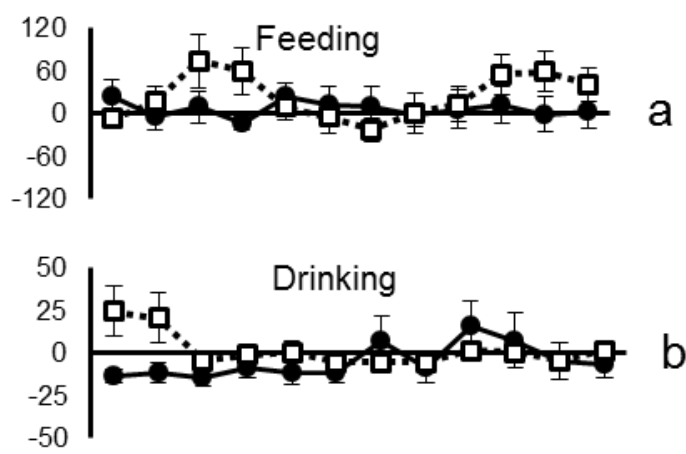

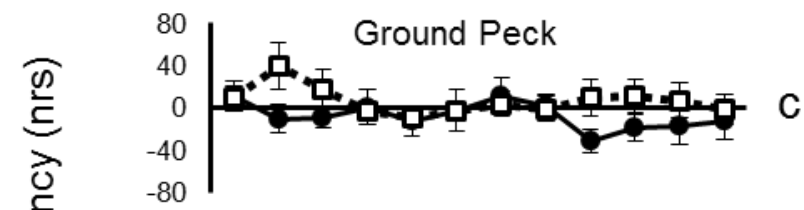

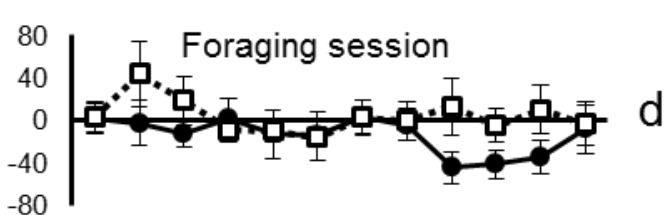

O

(⿻)

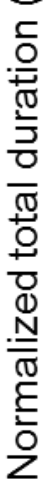
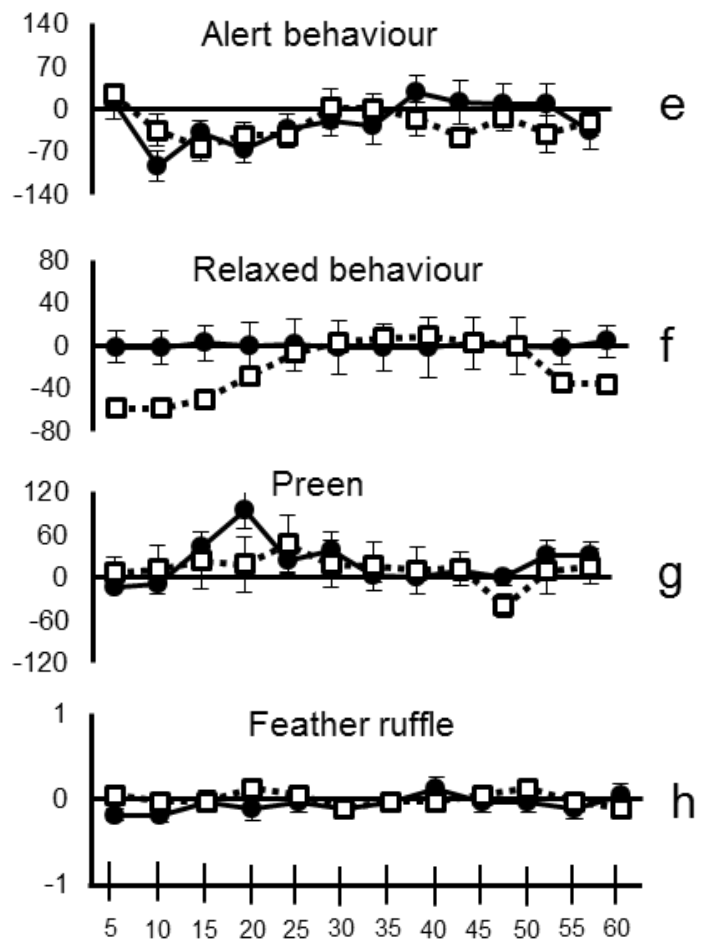
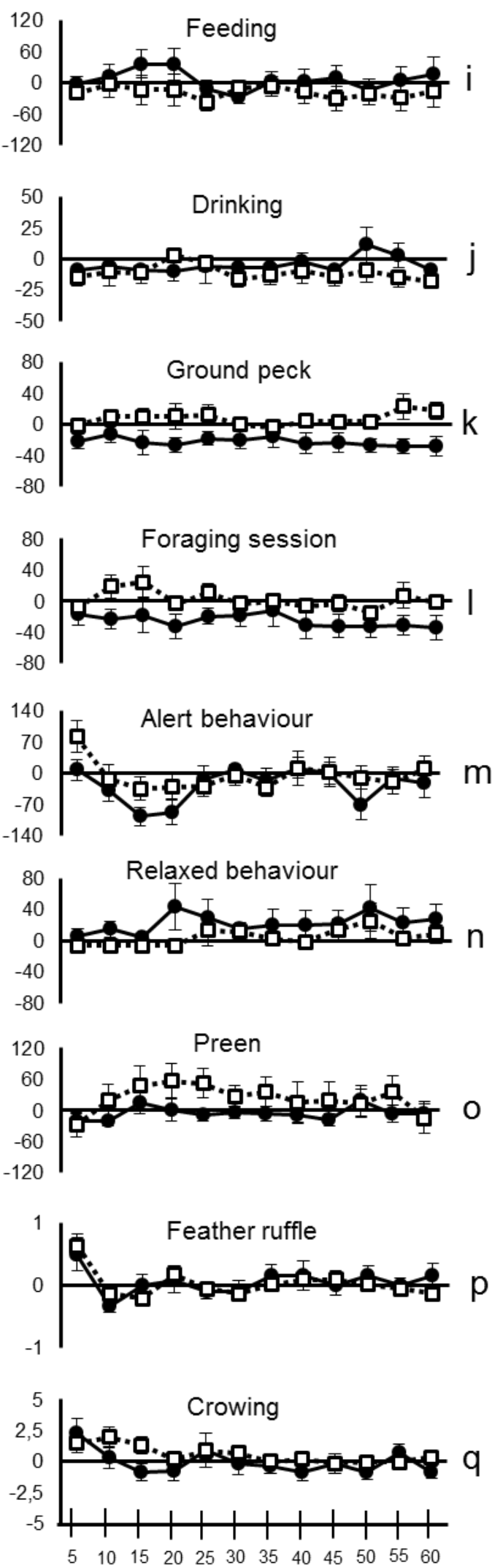

Time (min after restraint) 

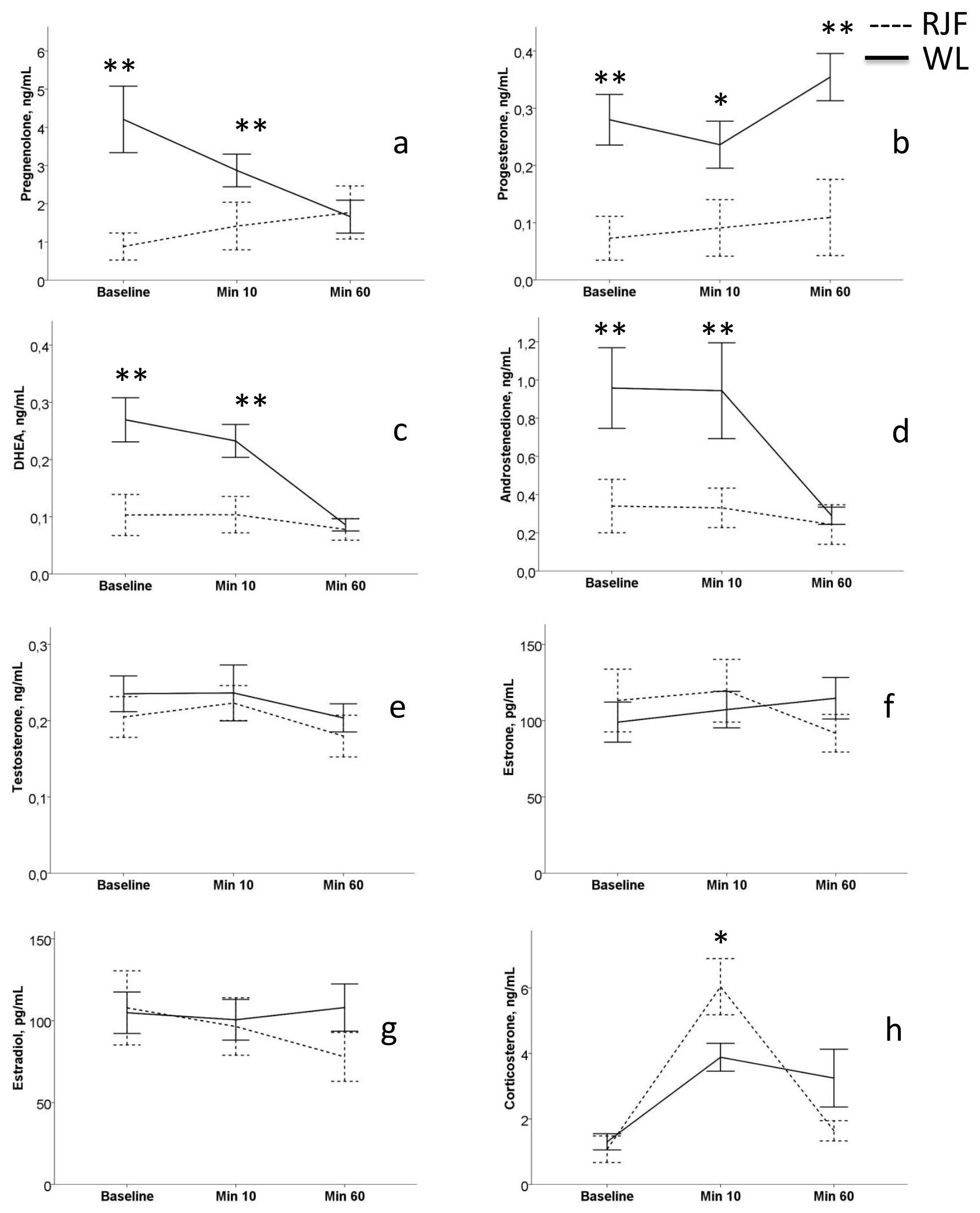